\title{
Simulation of Triaxial Compressional Behaviour of Sand based on State Concept
}

\author{
Er.Prabhat Kumar Jha ${ }^{1}$ \\ Department of Roads \\ Nepal
}

\begin{abstract}
An elastic-plastic constitutive model, which account for the combined influence of density and effective stress in a unique way, is developed for the triaxial compressional behaviour of sand under monotonic loading. The research addresses many important issues relevant to sandy soil behaviour and represents a unite experimental and theoretical effort to develop a constitutive model for sandy soils comprising balanced features of accuracy, simplicity and versatility. Particular attention in both experimental and theoretical considerations is given to the effects of density and effective stress as well as their combined influence on the sandy soil behaviour.

A distinct feature of the constitutive model of the research is that a single set of values of the material parameter is used to model the behaviour of the given sand. The parameters of this relation are expressed as function of an index parameter established in the framework of the steady state of deformation concept. The parameter employed in the relation is the State Index, $I_{s}$ which characterizes the sandy soil behaviour by accounting for the combined effects of the density and effective stresses related to a given initial fabric.

The elastic-plastic constitutive model is developed in the framework of the incremental theory of plasticity. The framework is developed by the modification of the torsional simple shear test framework, in stress space definition, yielding criterion, stress-dilatancy relationship, plastic modulus, and loading index. The model is defined in a stress space that enables to account failure surface which incorporates the effects of density and effective stress.
\end{abstract}

The accuracy and effectiveness of the elastic-plastic constitutive model is assessed through a comparison of the measured and predicted behaviour of the Bagmati sand as well as the Toyoura sand in monotonic triaxial test. The model correctly predicts the stress-strain characteristics observed in the undrained triaxial compression tests on medium dense, loose, very loose sand, providing gradual change in these characteristics from those typical for dense sand, with continuous increase of the shear stress with straining, to those typical for loose sand, with drop in the shear stress associated with developmenat of the large strains including the extreme cases with zero residual strength.

Keywords-Constitutive Model; Sandy Soil Behaviour; State Index; Bagmati Sand

\section{INTRODUCTION}

The need to solve increasingly sophisticated soil engineering and soil-structure interaction problems has created a demand for better experimental devices and techniques as well as better analytical tools, in order to have more clear understanding and representation of soil behavior. In the recent years, considerable experimental and theoretical efforts have been made to research and model the soil behaviour under various loading conditions, including cyclic loads as caused by earthquakes, traffic and sea wave loads. On the other hand, intensive research has also been done on its monotonic behavior, providing abundant valuable information on the essence of soil behaviour from very small strains with nearly elastic behaviour up to large deformations and flow of the material.

The rapid development in the recent years of advanced computation procedures for nonlinear stress analysis, such as the finite element method, especially emphasized the need for appropriate constitutive models, undoubtedly a crucial element in the numerical analysis. The development of more advanced constitutive models for soils has also been stimulated and thoroughly supported by the increasing supply of high quality experimental evidence and a continuous widening of our knowledge of soil behavior. A considerable challenge is posed, however, by the fact that soil behaviour is remarkably complex, involving various complicated processes and phenomena both under monotonic and cyclic loading.

Constitutive modeling of soils confronts two opposing requirements: on the one hand, the model should be able to describe the extreme complexity of soil behavior, and on the other hand, it should be comprehensible and simple enough to assure easy implementation in numerical analysis and application to practical problems. Whether complexity or simplicity will prevail is the first important decision to be made in the process of the development of a constitutive model. Yet, this judgment and the choice of the relevant aspects of the soil behaviour that should be modeled is probably the most critical for the accuracy, effectiveness and applicability of the model.

It is general trend in elastic-plastic sand models, however, that neither density nor the combined influence of density and normal stress is considered as a variable. In fact, a sand with different densities is regarded as a different material, and the effects of the normal stress are considered to be independent of the density. Roscoe and Poorooshasb (1963) were the first to emphasize the importance of the combined influence of density and normal stress on soil behavior. On the basis of both theoretical and experimental considerations, Roscoe and Poorooshasb introduced the critical state of the soil as a reference for quantification of the effects of the initial state on soil behavior. Here, the initial state refers to the void ratio and the mean normal stress of the soil prior to shearing. In a similar vein, Been and Jefferies (1985), Bolton (1986), Ishihara (1993) and Verdugo (1992) have reported extensive studies on the combined influence of the initial density and normal stress on sand behaviour. A distinctive feature of these studies is that particular indices and parameters serving as measures for the effects of the initial state on sand behaviour 
have been proposed. The proposed relative Dilatancy index $I_{\mathrm{r}}$ (Bolton, 1986), the state parameter (Been and Jefferies, 1985) and the state index $I_{S}$ (Ishihara, 1993; Verdugo, 1992) integrate the effects of the density and normal stress into a single parameter and as such, they are different from the commonly used parameter, the relative density $D_{\mathrm{r}}$.Recently, several attempts have been made to use the state parameter and the state index $\mathrm{I}_{\mathrm{s}}$ for sand modelling (Jefferies, 1993; Cubrinivski, 1993; Wood et al., 1994). Jefferies (1993) incorporated the state parameter as a hardening parameter in the Cam clay model to describe monotonic behaviour of sand and Wood et al. (1994) used the same parameter for modelling drained monotonic stress-strain behaviour associated with strain softening. Ishihara and Cubrinovski ( 1998 ) have simulated the undrained behaviour of sand using their modified hyperbolic relation along with the stress Dilatancy relation based on the energy approach of Roscoe et al 1963, and Gutierrez ( 1993 ) flow rule, in plane strain case.

The research deals with the sandy soils and presents an integrated experimental and theoretical investigation on their behaviour under monotonic loading conditions. The research contains all the necessary steps in evaluation of a constitutive model for sandy soils, including experimental research where the experimental basis for the model is produced, then development of a stress-strain relation, formulation of an elastic-plastic constitutive model, verification of the model. The present research model follows the framework of the state concept, in which a relative initial state with respect to some reference states of sand (Critical or Steady state; Quasi-steady state) is used for characterization of sand behavior.

\section{Constitutive Modelling}

Without aiming to review present constitutive models for sandy soils at this point, a brief discussion on the general trends in the modeling and basic requirements that a constitutive model has to fulfill will be given. To start with, it is important to recognize the existence and the need of various types of models since there are considerable difference as regards the purpose of the model, the problem that it considers and the required level of accuracy and simplicity among others. The development of the advanced constitutive models has already been under way for several decades, and these models have passed well beyond the speculative or qualitative description of soil behavior. During this period, a great number of constitutive models have been proposed involving various theories and concepts. Those concepts are either of a micromechanical or phenomenological nature. Even tough the principal feature of soils is their particulate structure and thus the ultimate adequate representation of the true nature of soils lies in the understanding of the microscopic behavior, the complexity of these processes and the diversity of the soil field conditions will definitely restrict the quantitative predictions of micromechanical models and especially their applicability in the foreseeable future. Therefore, it is quite understandable that the majority of the present advanced constitutive models rely on phenomenological or macroscopic observations of soil behavior. Only, these will be of interest in the present work.
Recent development in the constitutive modeling of the sandy soils and characterized by usage of a variety of approaches and theories including elasticity, viscosity and plasticity, as well as combinations of these theories: visco-elasticity, viscoplasticity and elasto-plasticity. This trend in the modeling is simply due to the fact that soils exhibit behaviour related to these theories. However, as pointed out earlier, it is crucial to select and model only the important aspects of the sandy soil behaviour that a constitutive model should cover, since that is the only approach which will contribute to the simplicity, comprehensibility, and applicability. That this has not been always done in frequent constitutive models is clearly indicated by the comment of Scott (1988) on the constitutive models presented at the workshop on Constitutive Equations for Granular Non- Cohesive Soils (Saada and Bianchini ,1988).

"Clearly, we cannot go on like this, with the ultimate goal of achieving a thermo-viscoelastic hypoplastic multiple critical bounding capped yielding endochronic state surface models. At some stage, physical intuition has to re-enter the problem...."

It has to be recognized, on the other hand, that plasticity models are already proved to be capable of capturing the important features of soil behaviour such as dilatancy, nonlinear and irrecoverable deformations, dependency on stress path and inherent and induced anisotropy among others. In fact, plasticity theory has been the cornerstone of the constitutive modeling of soils for more than two decades. The balance between the simplicity and accuracy of a constitutive model seems to be more or less achievable within the framework of the incremental theory of plasticity.

The requirements that a particular model has to fulfill are strongly dependent on the purpose of the model and in particular on the problem that it aims to solve. However, in general, the model has to satisfy theoretical, experimental and computational requirements. In other words, besides the requirements for theoretical rigors, it is essential to model the soil behaviour on a physical relevant basis in order to attain a realistic representation of the soil behaviour and versatile model. No less important is the fact that the number of the model parameters should be reasonable and that their experimental evaluation can be easily assessed in conventional tests. Computational efficiency and memory requirements are certainly features that can seriously influence the applicability of a constitutive model.

\section{Sandy Soil Behavior}

The behaviour of the granular materials can normally be accurately characterized for the practical application from the results of the drained tests, since in many problem, the material can usually be considered fully drained. However, if the rate of loading is very high, such as those resulting from explosions or earthquakes, or the permeability of the cohesionless soil is relatively low, as in fine sands or silts, undrained conditions can exists. If the material possesses low relative density, pore pressure increments, may result from these undrained conditions. This in turn may lead to instability, liquefaction, and failure earth dam and submarine. Slope failure has been attributed to the development of 
undrained condition in loose, fine sands and silts. These catastrophic failures illustrate the importance of understanding the undrained behaviour of sand.

Undrained monotonic loading of saturated cohesionless materials has been primarily used to investigate the mechanics of the soil instability and liquefaction. The requirement for soil instability and liquefaction are that a saturated, cohesionless soil exhibits significant contractive volume change tendencies during the undrained shearing with increase in the positive excess pore pressure such that continuously decreasing effective stress results as shearing progress. This can be achieved by shearing very loose soil at low as well as high initial confining pressure, but it can also be realized by shearing the dense specimen at high initial confining pressure. When sand is subjected to a monotonic or cyclic shear load it exhibits very complex behaviour which is governed by the coupling between the shear and the volumetric strains. The link between the distortional and volumetric strains is certainly the most distinctive feature of the deformation characteristics of granular materials. In accordance with this feature the behaviour of sand is profoundly affected by the initial density and fabric of packing, as well as by the initial normal and shear stresses. In other words, given sand behaves either in contractive or dilative manner and shows different cyclic strength or resistance to liquefaction depending on the initial packing and stress conditions.

\section{Triaxial Shearing}

Without any doubt, the triaxial test on cylindrical specimen is presently the most widely used procedure to evaluate several important properties of the soil behavior such as: strength, dilatancy, stress-strain relationship and anisotropy among others. The triaxial test has been used for research as well as for design projects and a very significant part of the present knowledge about soil behavior comes from triaxial test results.

In the conventional triaxial test, the sample is cylindrical in shape, laterally surrounded by a rubber membrane and vertically enclosed by rigid end platens through which the axial loading is applied. This configuration immediately creates specific boundary conditions that, as in any other laboratory test device, are different from the field conditions. This shortcoming has been accepted due to the fact that the field conditions cannot be exactly known nor can they be completed simulated by any laboratory test. In this sense, laboratory measurements have always to be seen an approximation of what may actually occur in the field.
Most probably, the world-wide use of the triaxial test in geotechnical engineering is because of some of the following advantages of this laboratory test (Baldi et al.1986): relative simplicity of drainage control and measurement of pore pressure, ability to apply principal stresses in known directions, ease of measuring axial and volumetric strains, use of solid cylindrical specimens which can be conveniently obtained from standard tube samples or easily trimmed from block samples, and versatility of the equipment which may be used for a variety of determinations besides triaxial strength and stiffness such as for instance, consolidation and permeability parameters, wave velocity, dynamic parameters and so forth. On the other hand, the conventional triaxial test has some limitations. Perhaps, the two most important are: the principal stresses can not be rotated continuously, but only by a sudden rotation of $90^{\circ}$, and it is not possible to have a truly generalized stress state, but at least, two principal stresses must to be identical. Consequently, the state of stresses is always axially symmetric.

State of Stress Conventional Tri-Axial Shearing Mode Tests

$$
\begin{gathered}
\{\sigma\}=\left(\begin{array}{ccc}
\sigma_{1} & 0 & 0 \\
0 & \sigma_{2} & 0 \\
0 & 0 & \sigma_{3}
\end{array}\right) \\
\Delta \sigma_{i, j}=\left[\begin{array}{ccc}
\Delta \sigma_{1,1} & 0 & 0 \\
0 & 0 & 0 \\
0 & 0 & 0
\end{array}\right] \\
\{\varepsilon\}=\left(\begin{array}{ccc}
\varepsilon_{1} & 0 & 0 \\
0 & \varepsilon_{2} & 0 \\
0 & 0 & \varepsilon_{3}
\end{array}\right) \\
\Delta \varepsilon_{i, j}=\left[\begin{array}{ccc}
\Delta \varepsilon_{1,1} & 0 & 0 \\
0 & \Delta \varepsilon_{2,2} & 0 \\
0 & 0 & \Delta \varepsilon_{3,3}
\end{array}\right]
\end{gathered}
$$

\section{RESEARCH METHODOLOGY}

\subsection{Stress-Strain Representation}

A major simplification applied to the constitutive relation to be developed is the limitation of the formulation to two dimensions. The cylindrical specimen of the conventional triaxial test is in axisymmetric stress state ( fig. 1 ). It is considered that the assumption of a two dimensional condition will avoid complicating the formulation significantly and yet on the other hand, will be appropriate for idealization of many in-situ loading condition within reasonable computational efforts and required accuracy. 


\subsection{Incremental Formulation}

The model is formulated in the X-Y-p space (fig. 2), where the stress variables are defined as; ( equ.1, 2 by K,H, Roscoe,

\section{A.N. Schofield, 1961 )}

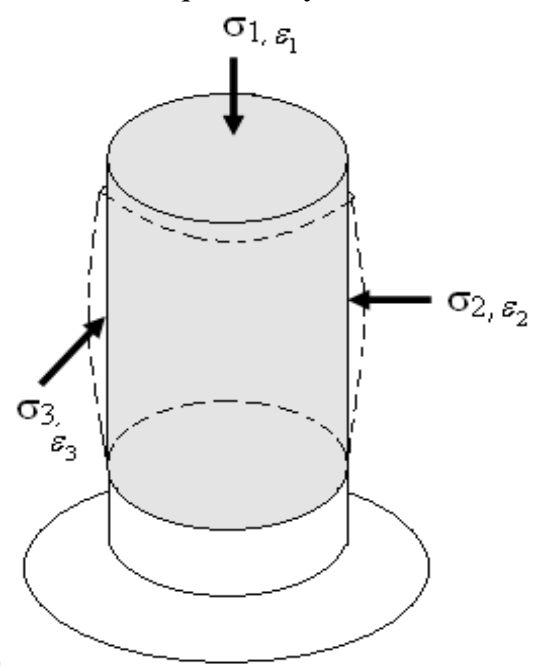

Fig. 1 State of stress, strain in triaxial compression test

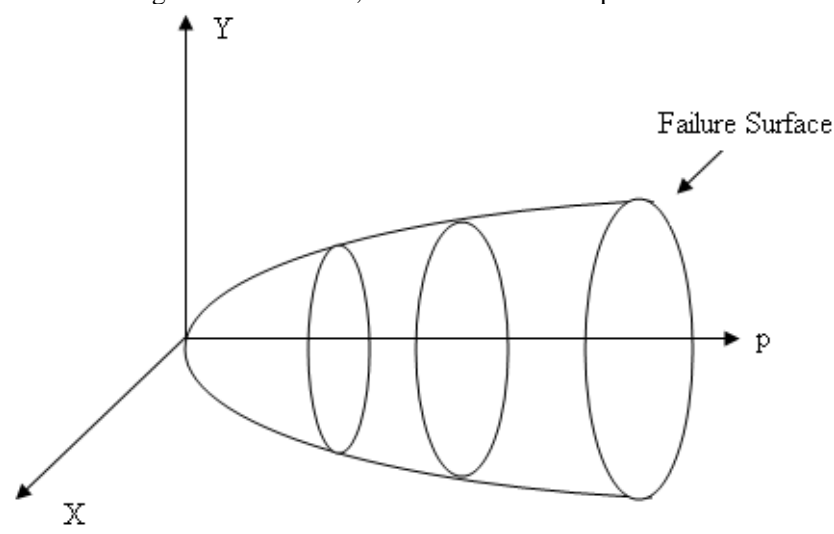

Fig.2 Typical shape of Failure surface in X-Y-p space ( K,H, Roscoe, A.N. Schofield, 1961 )

$X=\frac{1}{\sqrt{3}}\left(\sigma_{1}+2 \cdot \sigma_{3}\right)$

$Y=\sqrt{\frac{2}{3}}\left(\sigma_{1}-\sigma_{3}\right)$

$X^{2}+Y^{2}=p^{2}\left(3+\frac{2}{3} \cdot \eta^{2}\right)$

$r=p \sqrt{\left(3+\frac{2}{3} \cdot \eta^{2}\right)}$

$r f=p \sqrt{\left(3+\frac{2}{3} \cdot \eta_{\max }^{2}\right)}$

$\eta=\frac{E_{N} \cdot \varepsilon_{q}^{p} \cdot \eta_{\max }}{\eta_{\max }+E_{N} \cdot \varepsilon_{q}^{p}}$, $p=\frac{1}{3}\left(\sigma_{1}+\frac{2}{\sqrt{3}} X-\frac{1}{\sqrt{1.5}} Y\right)$

$q=\left(\sigma_{1}-\frac{1}{\sqrt{3}} X+\frac{1}{\sqrt{6}} Y\right)$

For the convention triaxial test with axisymmetric stress state,

$d \varepsilon_{q}=\frac{2}{3}\left[d \varepsilon_{11}-d \varepsilon_{33}\right]$

(9)

Since, in case of undrained shearing, $d \varepsilon_{V}$ is zero, which suggests $d \varepsilon_{q}=d \varepsilon_{11}$, i.e. axial strain is similar to the shear strain.

The failure surface, $\mathrm{f}(\mathrm{X}, \mathrm{Y})=0$ can be expressed as

$f=\left\{X^{2}+Y^{2}\right\}^{1 / 2}-r_{f}^{2}=0$

To start, it is assumed that the total strain increment $d \varepsilon_{i j}$ is decomposed into elastic and plastic components $d \varepsilon_{i j}^{e}$ and $d \varepsilon_{i j}^{p}$ by a simple superposition ,

$$
d \varepsilon_{i j}=d \varepsilon_{i j}^{e}+d \varepsilon_{i j}^{p}
$$

The elastic and plastic strain increment components are calculated separately, by an elastic stress-strain law of the form,

$d \sigma_{i j}=E_{i j k l} \cdot d \varepsilon_{k l}^{e}$

Where,

$E_{i j k l}=\frac{2 G_{e} \cdot v}{1-2 v} \delta_{i j} \cdot \delta_{k l}+G_{e}\left(\delta_{i k} \cdot \delta_{j l}+\delta_{i l} \cdot \delta_{j k}\right)$

$v$ is Poisson's Ratio,

$\delta_{i j}=$ Kronecker Delta $\left(\delta_{i j}=0\right.$ if $i \neq j$, and $=1$ for $i=j$ ),

$G_{e}$ is Elastic Shear Modulus, dependence on the e-p-plane and empirically defined as ( Iwasaki and Tatsuoka, 1977 )

$G_{e}=A \cdot p_{a} \cdot \frac{(2.17-e)^{2}}{1+e}\left[\frac{p}{p_{a}}\right]^{n}$

Where, $\mathrm{A}$ is dimensionless parameter, $p_{a}$ is atmospheric pressure $\left(1 \times 10^{4} \mathrm{Kpa}\right)$, $\mathrm{p}$ is the mean normal stress, $\mathrm{n}$ is the dimensionless material parameter determining the variation of $G_{e}$ with p. Thus, for triaxial case,

$d \sigma_{11}=\frac{G_{e}(2-3 \cdot v)}{1-2 v} \cdot d \varepsilon_{11} \quad, d \sigma_{22}=0, d \sigma_{33}=0, d \sigma_{12}=0$ 
The incremental plastic relations are given by

$d \varepsilon_{i j}^{p}=\langle L\rangle \frac{\partial g}{\partial \sigma_{i j}}$

Where, direction of plastic strain increment is specified as the normal to the plastic potential, g whereas the magnitude of plastic strain increment is given by the loading index , $\mathrm{L}$.

Finally, the general expression for the plastic strain increment can be written as,

$d \varepsilon_{i j}^{p}=\frac{1}{\mathrm{H}_{\mathrm{P}}} \cdot\left[\frac{\partial f}{\partial \sigma_{i j}} \cdot d \sigma_{i j}\right] \cdot \frac{\partial g}{\partial \sigma_{i j}}$

The total strain increment can be calculated as

$$
d \varepsilon_{i j}=E^{-1} i j k l \cdot d \sigma_{k l}^{e}+\frac{1}{\mathrm{H}_{\mathrm{P}}} \cdot\left[\frac{\partial f}{\partial \sigma_{i j}} \cdot d \sigma_{i j}\right] \cdot \frac{\partial g}{\partial \sigma_{i j}}
$$

Since, our experiment is strain controlled, so its necessary to model a strain controlled simulation.

$$
d \sigma_{i j}=E_{i j k l} \cdot\left\{d \varepsilon_{k l}-\frac{1}{\mathrm{H}_{\mathrm{p}}} \cdot\left[\frac{\partial f}{\partial \sigma_{i j}} \cdot d \sigma_{i j}\right] \cdot \frac{\partial g}{\partial \sigma_{i j}}\right\}
$$

The calculation of the plastic strain increment components in the framework of the incremental theory of plasticity is based on definition of the yield function, plastic potential function, and hardening function. The stress-dilatancy relationship for the case of triaxial shearing, given by Dafalias (1999) is used in the formulation.

The loading index, $\mathrm{L}$ is

$$
\mathrm{L}=\frac{1}{2 \cdot \mathrm{H}_{\mathrm{P}}} \cdot\left[-\eta+\frac{X_{C}}{r_{f}}\right]
$$

And,

$$
H_{p}=\left\{E_{N}-f \cdot \frac{d \varepsilon^{p}}{0.01}\left(E_{N}-E_{N, \text { min }}\right)\right\} \times\left\{1-\frac{r}{r_{f}}\right\}^{2} \times p
$$

Where, $\mathrm{H}_{\mathrm{P}}$ is plastic modulus, and $l$ is loading surface. Along the loading surface, plastic modulus is constant. The loading surface which is moving in the stress space, $\sigma_{i j}$, according to the load increments, is used to evaluate the current magnitude of the plastic modulus as well as to trace the loading intensity. It has to notice that the $G_{N}$ is the initial modulus whereas, $\mathrm{H}_{\mathrm{P}}$ is the tangential plastic modulus.

\subsection{Material Parameters Determination}

A distinct feature of the constitutive model of the present study is that a single set of values of the material parameter is used to model the behaviour of the given sand. That is whatever is the relative densities of the sand and the confining stress, the values of the material parameters remain the same. Thus, it is a prerequisite to use a determination procedure and to evaluate material parameters which will able resonablely accurately overall representation of a given sand. In general, except for the elastic parameters, the model parameters are dependent on the fabric of packing. And, except the mean normal pressure of the reference lines, all the parameters are dimensionless. The model requires four groups of parameters.

$>$ Elastic parameters.

$>$ State lines (reference states).

$>$ Stress strain parameters.

$>$ Dilatancy parameters.

\subsubsection{Elastic parameters.}

There is no specific requirement for the evaluation of the elastic parameters, and insistence on determination of these parameters at very small strain levels is not necessary since modeling of small strain behaviour is not attempted herein. Moreover, the Poisson's ratio and the exponent, $\mathrm{n}$ may be assigned fixed value of $0.2-0.3$ and $0.5-0.6$ respectively. The shear constant, $\mathrm{A}$ is back calculated from known value of elastic shear modulus, $G_{e}$; equation 14 .

The empirical relation for $G_{e}$ in undrained case is given by (Hicher, Pierre-Yves, 1994 );

$$
G_{e}=\frac{450 \sqrt{p^{\prime}}}{e} \cdot \frac{\left(1+v_{u}\right)}{1+v}
$$

Where, $v_{u}$ is the Poisson's ratio in undrained condition $(=0.5)$ for perfectly saturated soil.

\subsubsection{Reference states.}

The state lines, the UR-lines and QSS-line, will be evaluated using results of several monotonic undrained strain controlled tests on loose samples having different void ratio with the only requirement being that in the course of the undrained shearing, the samples will exhibit drop in the shear stress or QSS. Assembling the quasi steady states from each test in the e-p' diagram, QSS- line will be drawn. If during the test of undisturbed soil samples, the requirement for drop in the shear stress often may not be satisfied, and in such case it will be necessary to replace the QSS-line with SS-line as a reference line.

Again, if the zero steady state cannot be directly observed in the undrained tests, the position of the UR-line ( threshold void ratio ) will be reasonably approximated in the e-p’ plane by extending either the QSS/SS -line to the point of the intersection with the void ratio axis. This point of intersection then denotes the void ratio $e_{U}$.

\subsubsection{Stress-strain parameters}

The stress strain parameters of the model consists of linear coefficients of the expressions,

$$
\begin{array}{lll}
\eta_{\max } \quad=a_{1}+b_{1} I_{s} & & , I_{s} \geq 0 \\
E_{N, \text { max }}=a_{2}+b_{2} I_{s} & & , I_{s} \geq 0 \\
E_{N, \text { min }}=a_{3}+b_{3} I_{s} & & , I_{s} \geq 0
\end{array}
$$


The coefficients, $a_{1}, b_{1}, a_{2}, b_{2}, a_{3}, b_{3}$ will be determined using results from a series of drained p-constant tests on samples with distinct relative initial states or samples having different values of the state index.

The peak stress ratio, $\eta_{\max }$ of each test will directly read off from the measured normalized stress strain curve and the initial plastic moduli, $E_{N, \max }$ and $\mathrm{E}_{N \text {,min }}$ will be determined either as the best fit small strain and large strain values respectively, in trial and error simulations of the experimental data or by establishing an experimental relationship between $E_{N}$ and $d \varepsilon_{q}^{p}$ ( Cubrinovski and Ishihara, 1998 ). For each test, the state index $I_{S}$ will be calculated using the reference line and the initial e-p state of the sample, and the values of $\eta_{\text {max }}, \mathrm{E}_{N \text {, max }}$ and $\mathrm{E}_{N \text {,min }}$ as defined above will be plotted verses $I_{S}$; these correlation with $I_{S}$ will be approximated with linear relationship and the coefficients, $a_{1}, b_{1}, a_{2}, b_{2}, a_{3}, b_{3}$ will be determined from these data arrangements.

\section{Computational Flow Chart}

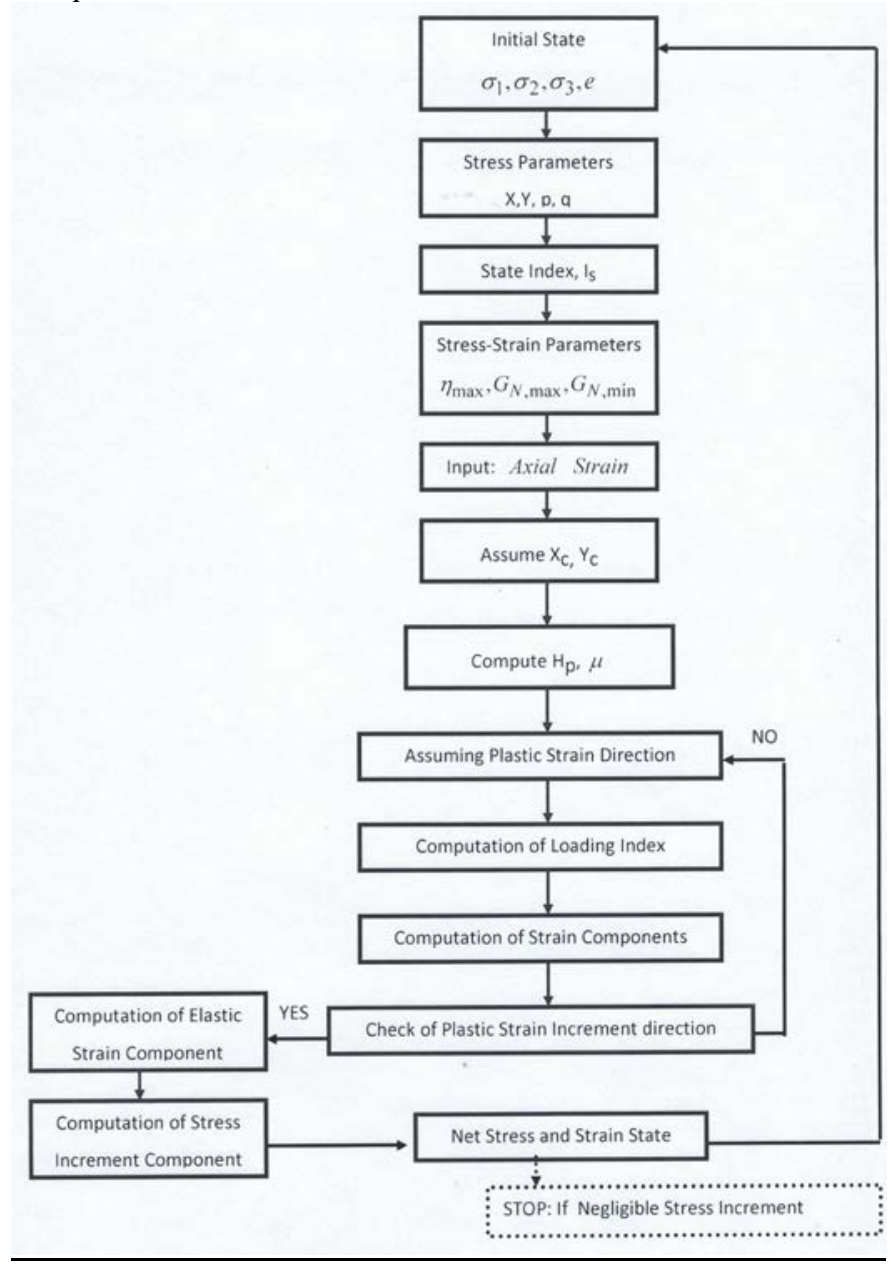

\subsubsection{Dilatancy parameters}

For the evaluation of dilatancy parameters, the critical state stress ratio, $M\left(=\frac{q}{p}\right)_{c s}$ will be first determined from the aforementioned monotonic undrained tests or alternately it may be approximated by the peak stress ratio of the drained tests, for $I_{S}=1$, or the final slope or slope at large strains of the curve, normalized plastic shear work versus plastic shear strain from drained tests. The parameter $\mu_{O}$ is the initial slope or slope at very small strains of the curve, normalized plastic shear work versus plastic shear strain from drained tests. The dilatancy parameter, $S_{C}$ which controls the pore pressure development and has an especially large influence on the cyclic strength. The parameter will be determined by mathematical corroboration due to absence of cyclic triaxial equipment in the laboratory, or can be determined as the value of the plastic strain at which average value of $\mu$ is attained.

For a larger value of $S_{C}$ reflects smaller $\mu$ at a given strain or less contractive behavior. The material parameters for the Bagmati sand will be used to model the monotonic behaviour of samples with various combinations of initial relative densities and confining pressure.

2.4 Physical Parameters of the Bagmati Sand (Bagmati River within Kathmandu Valley)

Maximum Void Ratio, $\mathrm{e}_{\max }=0.946$

Minimum Void Ratio, $\mathrm{e}_{\min }=0.610$

Effective Size, $\mathrm{D}_{50}=0.6 \mathrm{~mm}$

Coeffi. of Uniformity, $\mathrm{C}_{\mathrm{U}}=2.65$

Coeffi of Curvature, $\mathrm{C}_{\mathrm{C}}=1.12$

$\%$ Fines $=$ less than $1 \%$

Specific Gravity, $\mathrm{G}_{\mathrm{S}}=2.68$

Source: Jha,2004

\section{RESULTS AND EVALUATION}

\subsection{Material Parameters of the model for Bagmati Sand}

\subsubsection{Elastic Parameters}

Since, small strain behaviour is not attempted; there is no specific requirement for the evaluation of the elastic parameters. The Poisson's ratio, $v$ and the exponent, $\mathrm{n}$ are fixed to be the value of 0.25 and 0.55 respectively. And, the shear constant, A is computed by the back calculation of equ.14 and 22, and found to be 245.31 . 


\subsubsection{Reference Line}

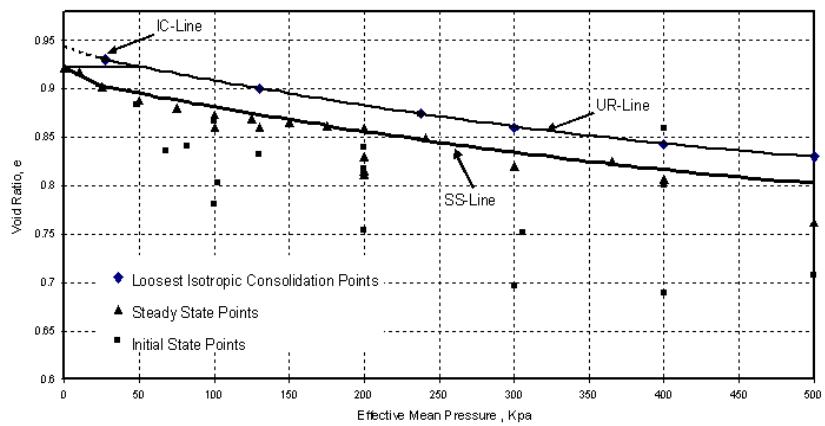

Fig. 3 Characteristic Curves of Bagmati Sand, ( Author, Karn,2005, Jha,2004 )

The characteristic curves of Bagmati Sand is shown in fig. 3, representing the loosest isotropic consolidation line ( IC- Line ), the steady state lines ( SS - Line ) and the upper reference line ( UR - Line ). The SS -line is best fitted from various set of void ratios and effective mean pressures at steady state of large number of drained and few undrained tests. These curves has been extended up to the effective mean pressure of 500 Kpa. The upper reference line is horizontal up to $50 \mathrm{Kpa}$, and after $50 \mathrm{Kpa}$, the IC - line serves as the UR - line. The IC line almost follows parallel to the SS-line. But, the UR- line for Toyoura sand is horizontal up to $400 \mathrm{Kpa}$. These lines are used for the computation of the state index.

\subsubsection{Stress - Strain Parameters}

The peak stress ratios and the corresponding tests state index are plotted . Though points are little scattered, it justifies linear relationship between these. The slope of the line $\left(b_{1}\right)$ is 0.0205, and the intercept ( $\left.a_{1}\right)$ is 1.39, ( fig. 4).

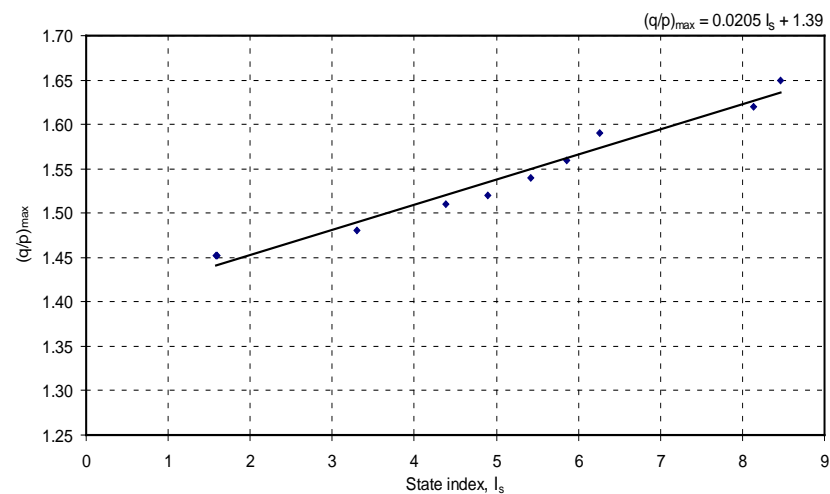

Fig. 4 Relationship between stress-strain parameters and state index for Bagmati Sand : Peak Stress Ratio ( Source:Author, Karn,2005, Jha,2004 )

Similarly, the normalized initial elastic modulus ( maximum and minimum ) and the corresponding tests state index are plotted ( fig. 5, and 6 ). Though points are little scattered, it justifies linear relationship between these. The slope of the line representing the relationship between $\mathrm{E}_{\mathrm{N} \text {,max }}$ and state index $\left(b_{2}\right)$ is 50 , and the intercept $\left(a_{2}\right)$ is 150 . And, the slope of the line representing the relationship between $\mathrm{E}_{\mathrm{N} \text {,min }}$ and state index ( $\left.b_{3}\right)$ is 13.20 , and the intercept $\left(a_{3}\right)$ is 68.57 .

\subsubsection{Dilatancy Parameters}

The normalized shear work has been computed for the Triaxial case for confining pressures $100 \mathrm{Kpa}, 200 \mathrm{Kpa}, 400 \mathrm{Kpa}$, and $500 \mathrm{Kpa}$, and plotted for corresponding plastic shear strain up to $27 \%$. The plot has justified the relation that the normalized work for various stress paths are approximately proportional to the shear strengths along those stress path ( fig.7 ).

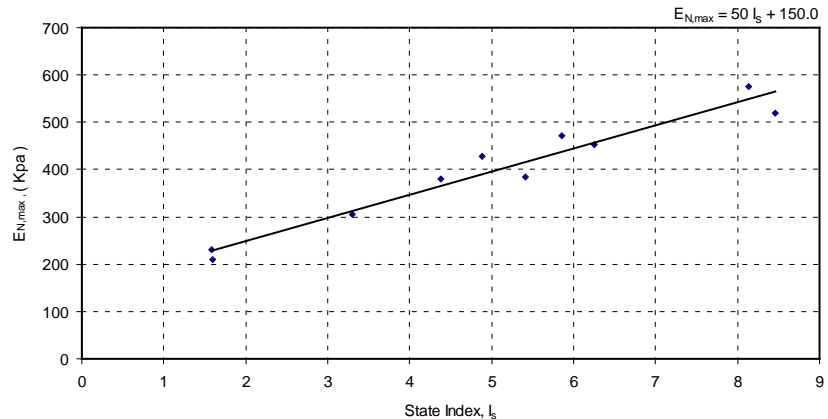

Fig. 5 Relationship between stress-strain parameters and state index for Bagmati Sand : Normalized Initial Elastic Modulus, $\mathrm{E}_{\mathrm{N}, \max }$ (Source:Author, Karn,2005, Jha,2004 )

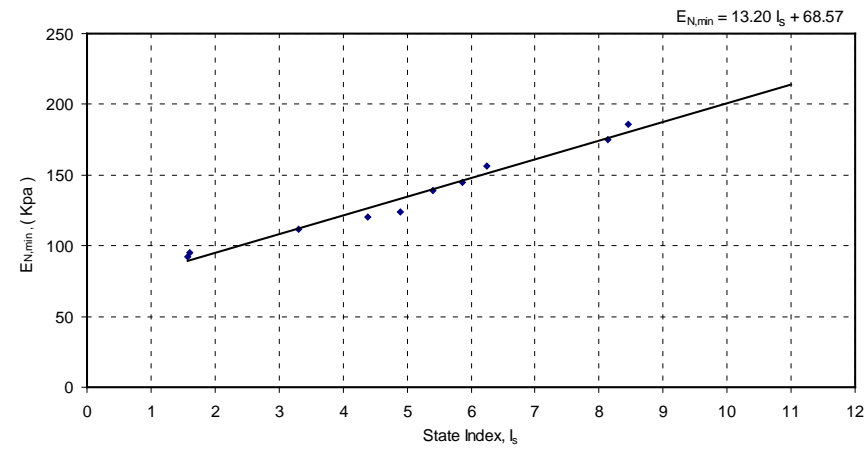

Fig. 6 Relationship between stress-strain parameters and state index for Bagmati Sand : Normalized Initial Elastic Modulus, EN,min (Source:Author, Karn,2005, Jha,2004 )

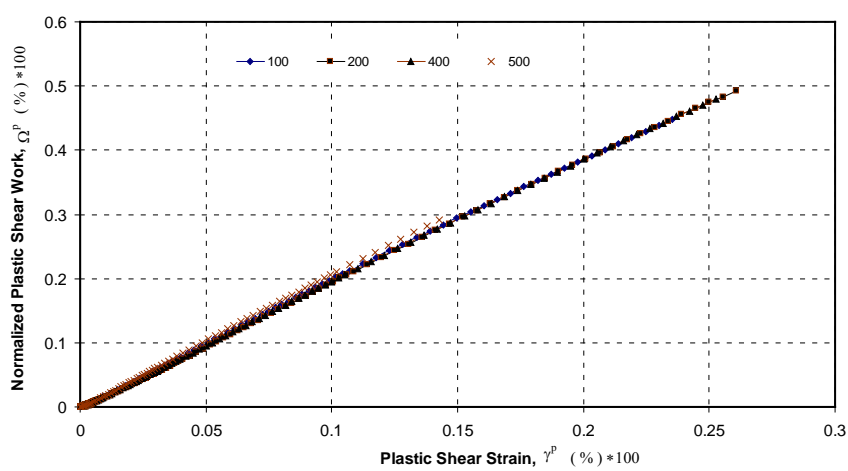

Fig. 7 Normalized shear work versus plastic shear strain relationship measured in monotonic drained Triaxial compression test on dry sample of Bagmati Sand with various initial e-p state ( $\mathrm{e}=0.682-0.863$ ) ( Source :Author, Karn,2005, Jha,2004 ) 


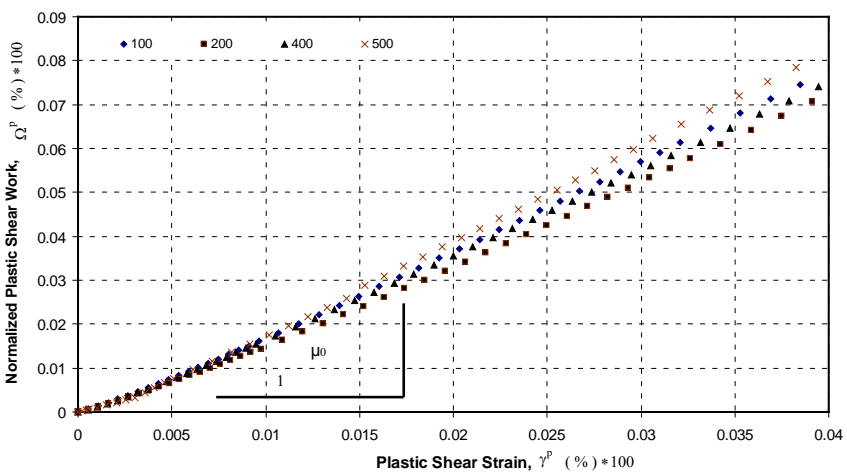

Fig 8 Normalized shear work versus plastic shear strain relationship measured in monotonic drained Triaxial compression test on dry sample of Bagmati

Sand enlarge view for small strain range (Source :Author, Karn,2005, Jha,2004 )

The dilatancy parameter,$\mu_{O}$ has been determined by the initial slope or say, slope at very small strains of the normalized plastic shear work versus plastic shear strain curve ( fig. 8 ), from drained tests, and found to be 1.057, which is much higher than that of Toyoura sand $(=0.22)$. The another dilatancy parameters, the critical state stress ratio, $M$ has been first approximated by the peak stress ratio of the drained tests, for $I_{S}=1$, and found to be 1.42. Again, it has been determined by the value of the final slope of the curve of normalized plastic shear work versus plastic shear strain from drained tests ( fig.7 ), and found to be the same, 1.42. This value is also much higher than that of Toyoura sand $(=0.607)$.

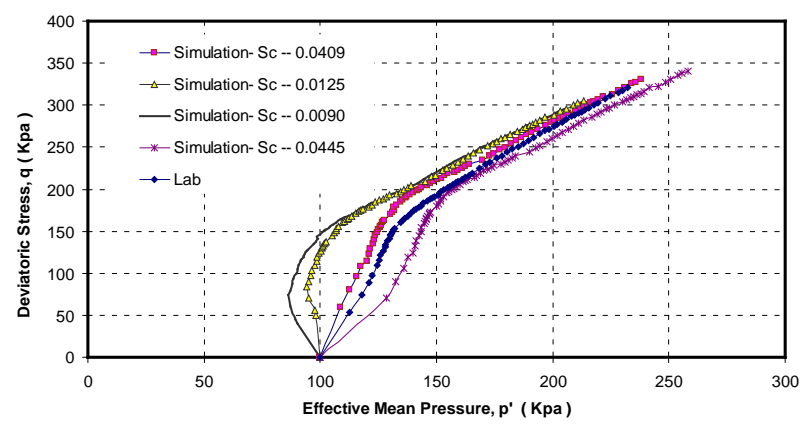

Fig. 9 Mathematical Corroboration for Sc - value for Bagmati Sand at confining pressure $100 \mathrm{Kpa}$

And, the final dilatancy parameter, $S_{c}$ which controls the pore pressure development has been determined to be 0.0410 as the value of the plastic strain at which average value of $\mu$ is attained ( fig. 7 ). Also, the mathematical corroboration for the parameter value determination has been performed with the trial $S_{c}$ values of $0.009,0.0125,0.0409$,and 0.0445 ( fig. 9 and 10 ), the predicted effective stress path ( ESP ) corresponding to the value 0.0409 seems to be closer to that of the laboratory results for both the confining pressures, $100 \mathrm{Kpa}$ and 200 Kpa. But, finally the value from laboratory $(=0.0410)$ is accepted for model simulation.

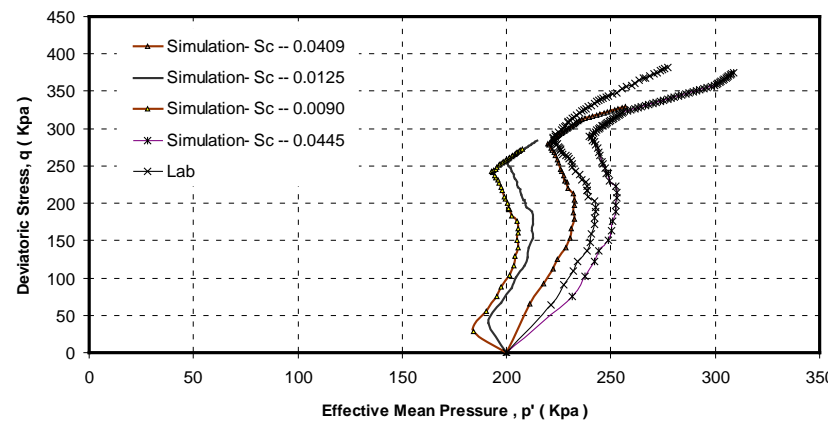

Fig. 10 Mathematical Corroboration for Sc - value for Bagmati Sand at confining pressure $200 \mathrm{Kpa}$

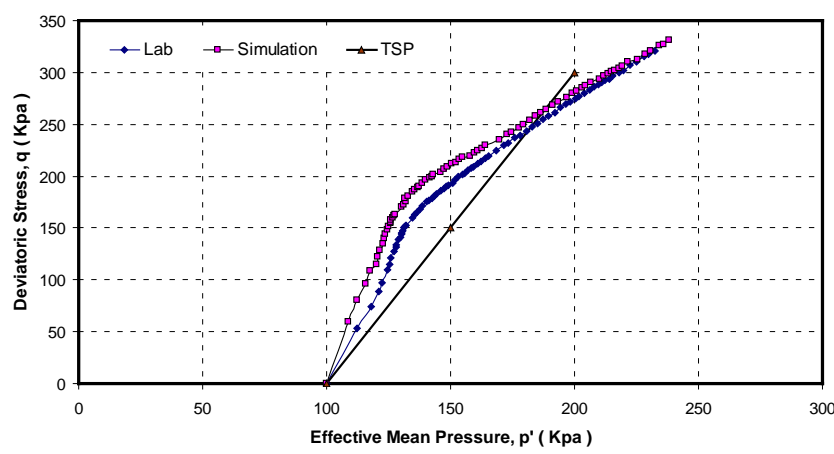

Fig. 11 Comparison of model simulation with undrained Triaxial test results on Bagmati Sand having void ratio of 0.779 and state index 4.96 at confining pressure $100 \mathrm{Kpa}$

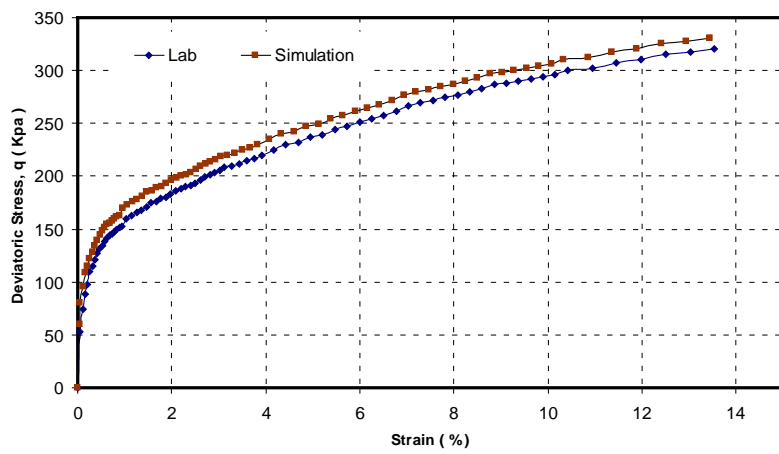

Fig. 12 Comparison of model simulation with undrained Triaxial test results on Bagmati Sand having void ratio of 0.779 and state index 4.96 at confining pressure $100 \mathrm{Kpa}$

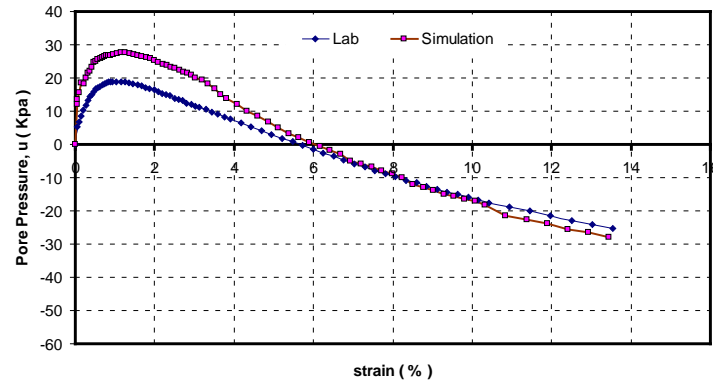

Fig. 13 Comparison of model simulation with undrained Triaxial test results on Bagmati Sand having void ratio of 0.779 and state index 4.96 at confining pressure $100 \mathrm{Kpa}$ 


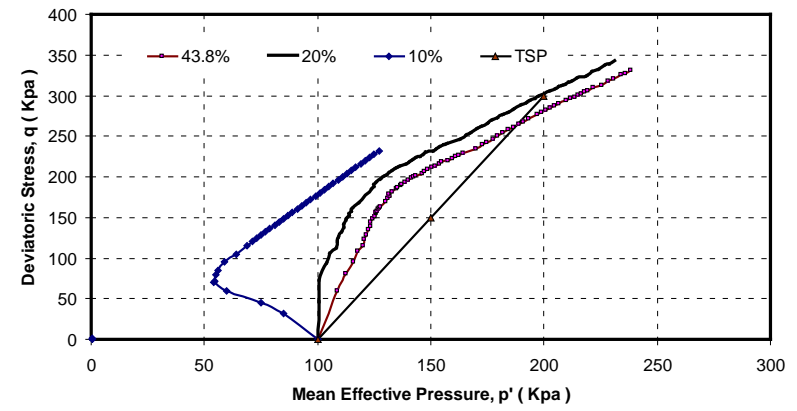

Fig. 14 Model simulations with undrained Triaxial test results on Bagmati Sand having relative density 10\%, 20\%, 43.8\% at confining pressure $100 \mathrm{Kpa}$

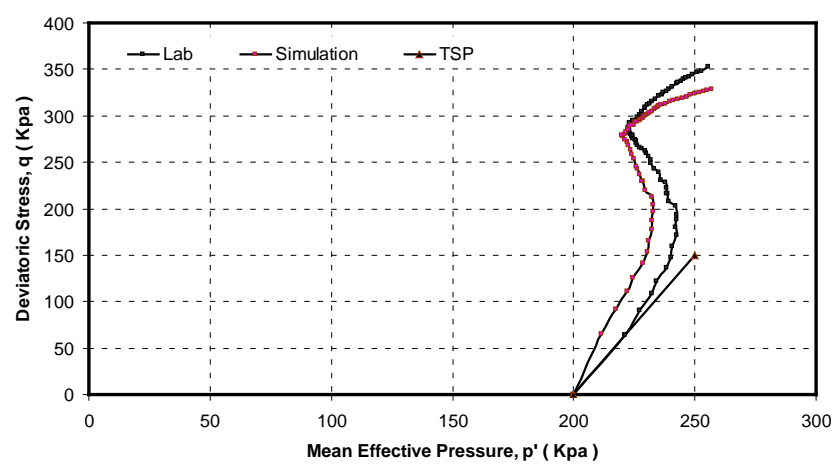

Fig. 15 Comparison of model simulations with undrained Triaxial test results on Bagmati Sand having void ratio of 0.754 and state index 5.16 at confining pressure $200 \mathrm{Kpa}$

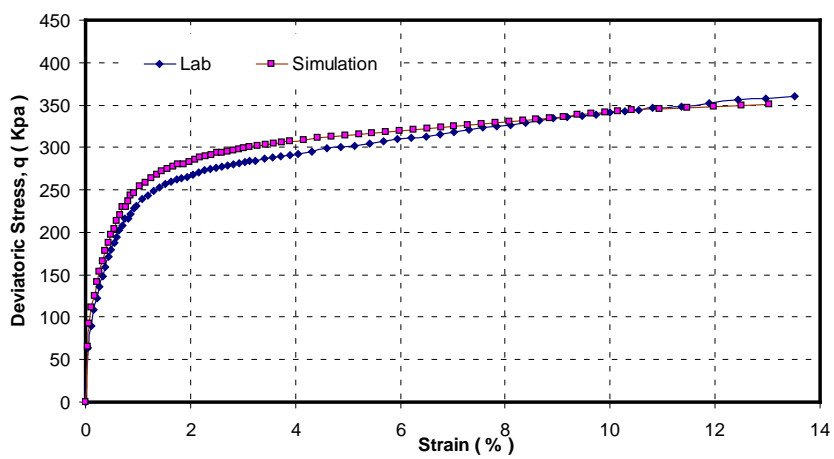

Fig. 16 Comparison of model simulations with undrained Triaxial test results on Bagmati Sand having void ratio of 0.754 and state index 5.16 at confining pressure $200 \mathrm{Kpa}$

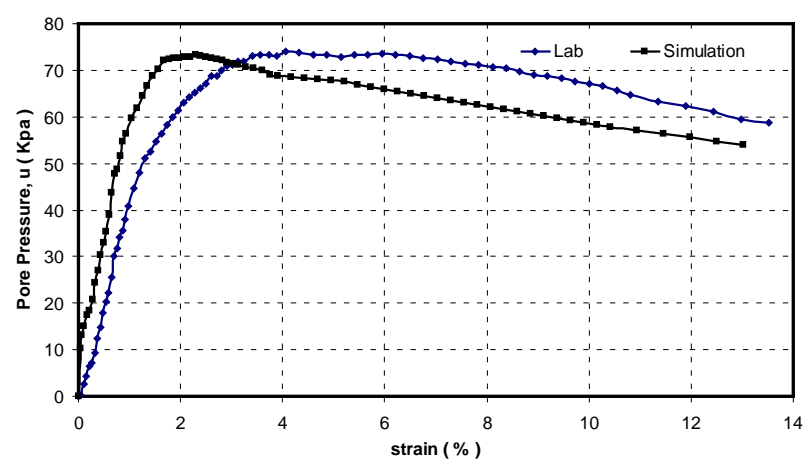

Fig. 17 Comparison of model simulations with undrained Triaxial test results on Bagmati Sand having void ratio of 0.754 and state index 5.16 at confining pressure $200 \mathrm{Kpa}$

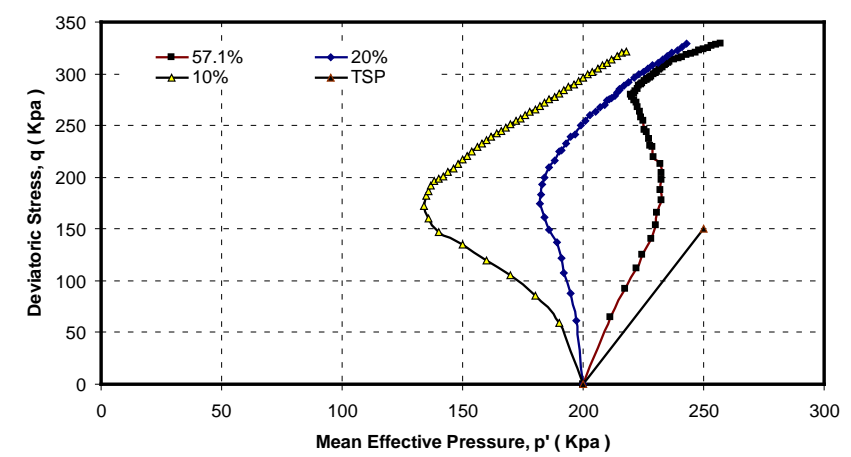

Fig. 18 Model simulations with undrained Triaxial test results on Bagmati Sand having relative density $10 \%, 20 \%, 57.1 \%$ at confining pressure $200 \mathrm{Kpa}$

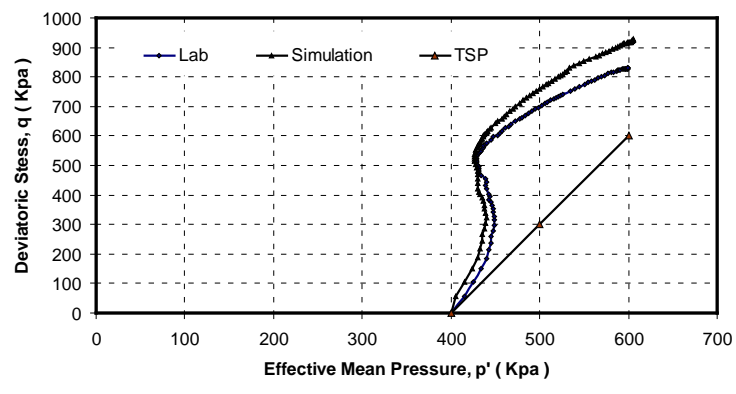

Fig. 19 Comparison of model simulations with undrained Triaxial test results on Bagmati Sand having void ratio of 0.802 and state index 1.54 at confining pressure $400 \mathrm{Kpa}$

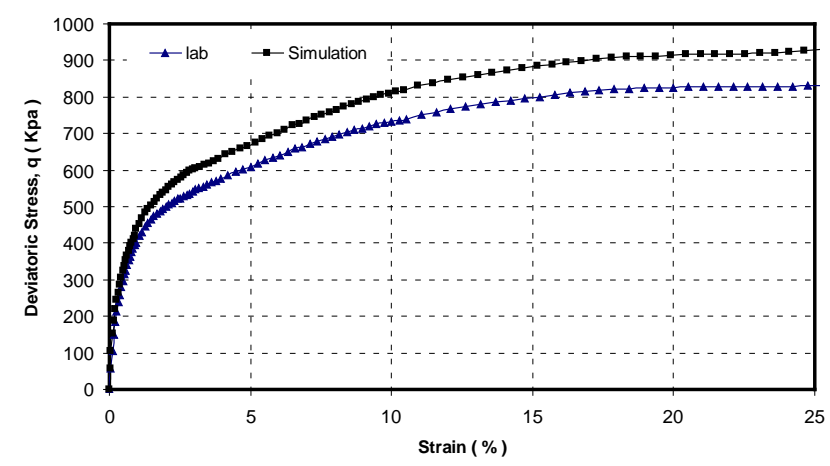

Fig. 20 Comparison of model simulations with undrained Triaxial test results on Bagmati Sand having void ratio of 0.802 and state index 1.54 at confining pressure $400 \mathrm{Kpa}$

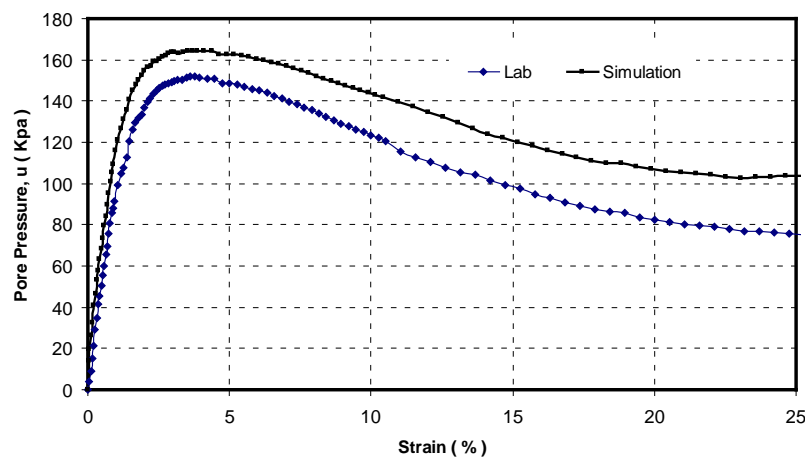

Fig. 21 Comparison of model simulations with undrained Triaxial test results on Bagmati Sand having void ratio of 0.802 and state index 1.54 at confining pressure $400 \mathrm{Kpa}$ 


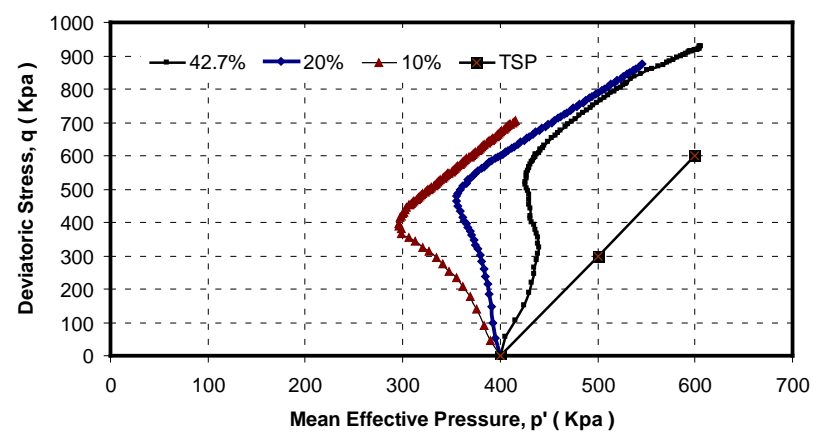

Fig. 22 Model simulations with undrained Triaxial test results on Bagmati Sand having relative density $10 \%, 20 \%, 42.7 \%$ at confining pressure $400 \mathrm{Kpa}$

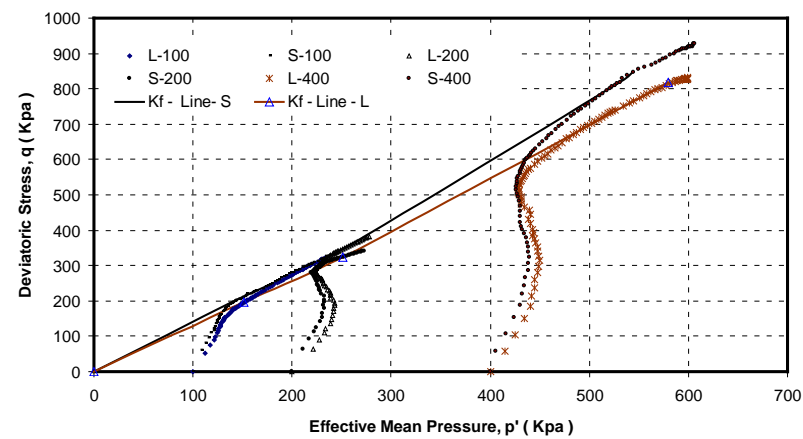

Fig. 23 Comparison of model simulations with undrained Triaxial test results on Bagmati Sand having void ratio of 0.779, 0.754, 0.802 and state index 4.96,

5.16, 1.54 at confining pressure 100, 200, 400 Kpa respectively

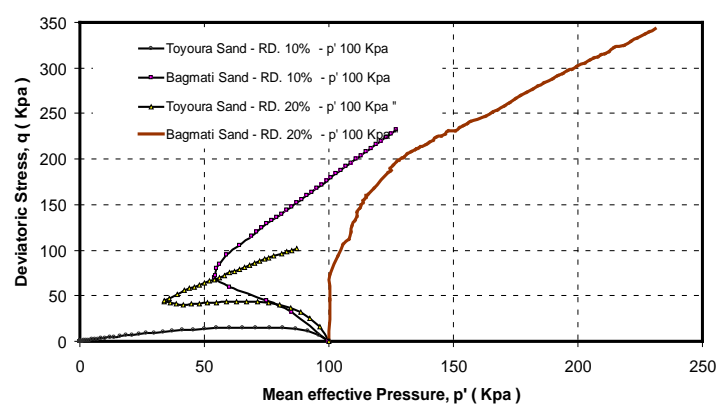

Fig. 24 Model simulations with undrained Triaxial test results on Toyoura Sand having relative densities $22.9 \%$ and $65.5 \%$ at confining pressure 100 respectively.

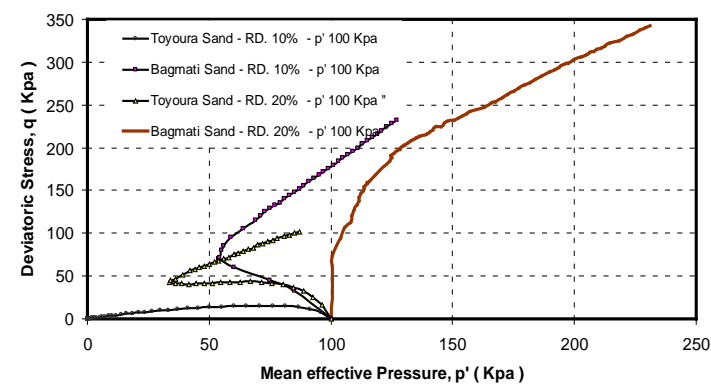

Fig. 25 Comparison of simulated results of Bagmati Sand and Toyoura Sand for relative density $10 \%$, and $20 \%$ at confining pressure 100 Kpa respectively

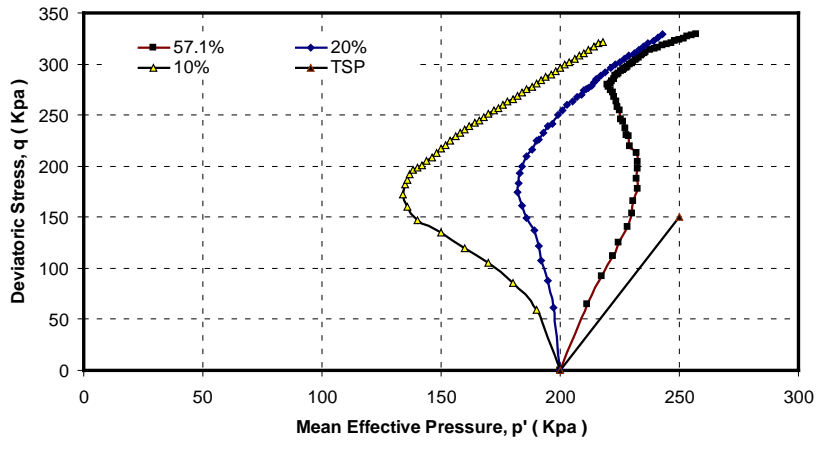

Fig. 26 Model simulations with undrained Triaxial test results on Bagmati Sand having relative density 10\%, 20\%, 57.1\% at confining pressure $200 \mathrm{Kpa}$

\subsection{Performance of Model}

For the verification and validation of the model, the predictions of the model are compared to the laboratory undrained monotonic loading of Bagmati sand, and also for Toyoura sand. For Bagmati sand, the experimental data is taken from Jha (2004), and for Toyoura sand, the experimental data is taken Mitsutoshi Yoshimine ( 1996 -1999 ). The data from the these tests comprise various aspects of the undrained behaviour of the sand and particularly emphasize the effects of density on stress-strain behaviour and effective stress path along the pore pressure development.

\subsubsection{Simulation for Bagmati Sand}

The tri-axial compressional behaviour of the Bagmati sand has been predicted for the three isotropic consolidation pressures, $100 \mathrm{Kpa}$, $200 \mathrm{Kpa}, 400 \mathrm{Kpa}$, and the relative densities $42.7 \%$, $57.1 \%$, $43.8 \%$, respectively. The simulation is also done for relative densities $10 \%$, $20 \%$. The simulation is done in strain controlled manner at a strain rater of $0.01 \mathrm{~mm}$.

Fig. 11 and fig. 12 shows the comparison between predicted and measured ( i.e. laboratory ) behaviour of isotropic consolidated the sand with relative density $42.7 \%$ and consolidation pressure of 100 Kpa. Apparently, good agreement between the predicted and measured behaviour is obtained for both effective stress path ( ESP ) and stress-strain curve. Initially contractive response associated with development of pore pressure and movement of the ESP toward right, approximately uniform 
All the material parameters are summarized in table 1.

\begin{tabular}{|c|c|c|c|}
\hline Relations & Material Parameters & Value for Bagmati Sand & Value for Toyoura Sand \\
\hline Elastic & Elastic parameters & $=$ & \\
\hline$\left(\mathrm{G}_{\mathrm{e}}, v\right)$ & $\begin{array}{l}\text { Shear Constant ( A ) } \\
\text { Poisson's Ratio ( } v \text { ) } \\
\text { Exponent ( } \mathrm{n} \text { ) } \\
\text { Reference lines }\end{array}$ & $\begin{array}{l}245.31 \\
0.25 \\
0.55\end{array}$ & $\begin{array}{l}250 \\
0.20 \\
0.60\end{array}$ \\
\hline $\begin{array}{l}\text { \{UR-Line, } \\
\text { SSL-Line }\end{array}$ & $\begin{array}{c}\mathrm{p}, \mathrm{e}_{\mathrm{S}}, \mathrm{e}_{\mathrm{UR}} \\
\text { (Kpa, fraction,fraction ) }\end{array}$ & $\begin{array}{l}(0.0,0.910,0.910) \\
(50,0.896,0.910) \\
(100,0.882,0.908) \\
(150,0.867,0.883) \\
(200,0.858,0.883) \\
(250,0.845,0.871) \\
(300,0.834,0.860) \\
(350,0.824,0.851) \\
(400,0.816,0.858) \\
(500,0.800,0.830)\end{array}$ & $\begin{array}{l}(0.0,0.895,0.895) \\
(30,0.873,0.895) \\
(50,0.870,0.895) \\
(100.0 .860,0.895) \\
(200,0.850,0.895) \\
(400.0 .833,0.895)\end{array}$ \\
\hline $\begin{array}{c}\left\{(\mathrm{q} / \mathrm{p})_{\max },\right. \\
\left.\mathrm{E}_{\mathrm{N}, \max }, \mathrm{E}_{\mathrm{N}, \min }\right\} \\
\text { Stress- Dilatancy }\end{array}$ & $\begin{array}{l}\text { Peak Stress ratio coefficients } \\
\left(a_{1}, b_{1}\right) \\
\begin{array}{r}\text { Max. Young's Modulus coefficients } \\
\left(a_{2}, b_{2}\right)\end{array} \\
\begin{array}{r}\text { Min. Young's Modulus coefficient } \\
\left(a_{2}, b_{3}\right)\end{array} \\
\text { Degradation parameters }(f) \\
\text { Dilatancy parameters }\end{array}$ & $\begin{array}{c}(1.39,0.0205) \\
(150,50) \\
(68.57 .13 .20) \\
4\end{array}$ & $\begin{array}{c}(0.58,0.023) \\
(230,15) \\
(79,16) \\
4\end{array}$ \\
\hline$\left\{{ }_{0}, \mathrm{M}, \mathrm{S}_{\mathrm{c}}\right\}$ & $\begin{array}{c}\text { Dilatancy coefficent, } \mu_{0} \\
\text { Critical state stress ratio, } \mathrm{M} \\
\text { Dilatancy strain, } \mathrm{S}_{\mathrm{c}} \\
\text { Source for Valt }\end{array}$ & $\begin{array}{c}1.057 \\
1.42 \\
0.0410 \\
\text { youra Sand: Cubrinovski. }\end{array}$ & $\begin{array}{c}0.22 \\
0.607 \\
0.0055 \\
\text { and Ishihara, Kenji (1998) }\end{array}$ \\
\hline
\end{tabular}

slope, until phase transformation state is reached, and then dilative response with further movement of the ESP toward right with lower uniform slope than the previous one. Up to 6 $\%$ of strain, there is development of positive pore pressure and only after $6 \%$, there is development of negative pore pressure, even though, the Bagmati sand dilates before $6 \%$ of strain. (fig. 12, and 13). This is due to the fact that negative pore pressure development due to shearing, is lesser than, due to increase in effective mean pressure ( i.e. mechanical phenomenon ). For the relative densities $10 \%$ and $20 \%$, the ESPs have been predicted, and even at $10 \%$ of the relative density, the Bagmati sand does not exhibit complete contractive behaviour at the confining pressure, $100 \mathrm{Kpa}$ (fig. 14). At $10 \%$, initially contractive response associated with development of pore pressure and movement of the ESP toward left, until phase transformation state is reached, and then dilative response with movement of the ESP toward right.

Similarly, fig. 15 and fig. 16 shows the comparison between predicted and measured behaviour of isotropic consolidated sand with relative density $57.1 \%$ and consolidation pressure of $200 \mathrm{Kpa}$. It may seen that good agreement between the predicted and measured behaviour is obtained for both effective stress path and stress-strain curve. Initially contractive response associated with development of pore pressure and movement of the ESP toward right concaving to the left, until phase transformation state is reached, and then dilative response with further movement of the ESP toward 
right with approximately uniform slope. The pore pressure development has been shown in fig. 17. Again, for the relative densities $10 \%$ and $20 \%$, the ESPs have been predicted, and even at $10 \%$ of the relative density, the Bagmati sand does not exhibit complete contractive behaviour at the confining pressure, $200 \mathrm{Kpa}$ ( fig. 18). At $10 \%$ and $20 \%$, initially contractive response associated with development of pore pressure and movement of the ESP toward left, until phase transformation state is reached, and then dilative response with movement of the ESP toward right.

Figure 19 and fig. 20 also show the comparison between predicted and measured behaviour of isotropic consolidated sand with relative density $42.7 \%$ and consolidation pressure of 400 Kpa. Good agreement between the predicted and measured behaviour is obtained for both effective stress path and stress-strain curve. Initially contractive response associated with development of pore pressure and movement of the ESP toward right concaving to the left, until phase transformation state is reached, and then dilative response with further movement of the ESP toward right with approximately uniform slope. The pore pressure development has been shown in fig. 21. Again, for the relative densities 10 $\%$ and $20 \%$, the ESPs have been predicted, and even at $10 \%$ of the relative density, the Bagmati sand does not exhibit complete contractive behaviour at the confining pressure, 400 Kpa ( fig. 22). At $10 \%$ and $20 \%$, initially contractive response associated with development of pore pressure and movement of the ESP toward left, until phase transformation state is reached, and then dilative response with movement of the ESP toward right

The failure envelops, represented by $\mathrm{K}_{\mathrm{f}}$ - line, are drawn for both the predicted as well as measured case, shown in fig. 23. These simulation and laboratory failure envelops gives the $\mathrm{M}$, i.e. q-p' stress at steady state, with corresponding values 1.42 , and 1.50. And, $M=\frac{6 \cdot \sin \phi_{s s}}{3-\sin \phi_{s s}}$ Finally, the angle of interparticle friction during steady state is calculated to be $35.03^{\circ}$, and $36.86^{\circ}$ respectively. Thus, the model gives little overestimated value of the inter-particle friction during steady state.

\subsubsection{Simulation for Toyoura Sand}

Also, the tri-axial compressional behaviour of the Toyoura sand has been predicted for the three isotropic consolidation pressures, $100 \mathrm{Kpa}$ and the relative densities $22.9 \%$, $65.5 \%$ respectively ( fig. 24). The simulation is done at strain rate of $0.01 \mathrm{~mm}$.

Fig. 24 shows the comparison between predicted and measured behaviour. The model also set good agreement between the predicted and measured behaviour for the sand, for both effective stress path ( ESP ) and stress-strain curve. At $22.9 \%$, initially contractive response with movement of the ESP toward left concaving to the left-down, until phase transformation state is reached, and then dilative response with further movement of the ESP toward right with approximately uniform slope. Similarly, at $65.5 \%$, initially contractive response with movement of the ESP toward concaving to the right, until phase transformation state is reached, and then dilative response with further movement of the ESP toward right with approximately uniform slope. At relative density $65.5 \%$, the pore pressure development due to the shearing phenomenon, is much lesser than that of due to the mechnical phenomenon.

\subsubsection{Comparison between Bagmati Sand and Toyoura Sand}

The behaviour of the Bagmati sand and Toyoura sand has been compared, and it is remarked that at $10 \%$ of relative density, the toyoura sand behaves fully contractive, where as the Bagmati sand shows contractive behaviour initially and then dilates ( fig.25 ) at $100 \mathrm{Kpa}$. But, for relative density $20 \%$, both behave similar behaviour with different magnitudes. This pictorial presentation reflects that for same relative density and confining pressure, Toyoura sand is more susceptible to liquefaction and flow deformation.

The model correctly predicts the stress-strain characteristics observed in the undrained triaxial compression tests on medium dense, loose, very loose sand, providing gradual change in these characteristics from those typical for dense sand, with continuous increase of the shear stress with straining, to those typical for loose sand, with drop in the shear stress associated with development at of the large strains including the extreme cases with zero residual strength.

\section{CONCLUSION AND RECOMMENDATION}

The research is an attempt to represent the triaxial undrained monotonic behaviour on a physically relevant basis and provide a constitutive model comprising balanced features of accuracy, simplicity, and versatility. The theoretical part of the study is focused on the development of a proper modeling concept in order to account for the combined effects of density and mean effective stress i.e. state index as state parameter, on the behaviour of cohesionless soils. The influence of various factors on the monotonic behaviour of sandy soils is accounted for in an elastic-plastic constitutive model as a close result of this work. The framework is developed by the modification of the torsional simple shear test framework, in stress space definition, yielding criterion, stress-dilatancy relationship, plastic modulus, and loading index.

\subsection{Characteristic Curves of Bagmati Sand}

The three characteristic curves of Bagmati sand; the loosest isotropic consolidation line, the steady state lines and the upper reference line, are achieved for the mean effective pressure up to $500 \mathrm{Kpa}$. With these curves reference, the flow and non-flow case can be assessed for the given initial state ( e, p ).

\subsection{Undrained Monotonic behaviour of Bagmati Sand}

For these three set of relative densities and isotropic consolidation pressure, the pore pressures development due to the dilation, are not so dominant over the mechanical phenomenon that it generates net negative pore pressure, except for $42.7 \%$ relative density and $100 \mathrm{Kpa}$ after $6 \%$ of strain. 
Though, its very much difficult to prepare a sample of $10 \%$ relative density and below, the behaviour of the sand is predicted, and even at this relative density and confining pressure up to $400 \mathrm{Kpa}$, the Bagmati sand does not exhibit complete contractive behaviour. It also conclude that the sand is less susceptable to liquefaction and flow deformation.

The failure envelops, $K_{f}$ - line, of Bagmati sand has slope $1.42: 1$, from the lab result, and the angle of inter-particle friction during steady state is and $35.03^{\circ}$.

\subsection{Performance and Application of the Model}

The model has ability to simulate undrained response from that typical of dense to that typical of loose sand including contractive flow or limited flow, for wide range of effective stresses. To check the effectiveness of the proposed model, simulated results are compared to the measured behaviour of sand in triaxial undrained monotonic tests. For the purpose, strain controlled version of the model are developed. Besides, the physical relevance of the model, it is important to emphasize the practical benefits arising from the fact that a single set of parameters characterizes the behaviour over a wide range of densities and stresses. Moreover, it is proved that the model is computationally efficient and has negligible computer memory requirements. The model can be applied for the various geotechnical studies like liquefaction, shear strength evaluation, residual strength evaluation, etc.

Key features of the proposed constitutive model can be summarized as follows :

a. The characterization of sand behaviour is based on the state concept via state index.

b. An energy based stress-dilatancy relation is employed.

c. The stress-strain-dilatancy model is incorporated into the elasto-plastic framework of sand modeling in order to establish a mathematical formulation.

d. The plasticity formulation includes the assumptions for continuous yielding and the dependence of the plastic strain increment direction on the stress increment direction.

e. The integration of the state concept and the elastoplasticity into a single framework leads to the unique capability of the model to capture the prominent features of sand behaviour over a wide range of density and stress states.

Since, the research is limited for the model simulation of triaxial undrained monotonic behaviour, it is recommended to extend the model framework for the triaxial undrained cyclic behaviour of sand.

\section{REFERENCES}

[1] Jha,Prabhat Kumar(2003)," Simulation of Triaxial Compressional Behaviour of Sand based on State Concept”,M.Sc. Thesis at Institute of Engineering, IOE/TU,NEPAL,

[2] Bardet, J.P. (1990), “Hypoplastic model for Sands .” Journal of Engineering Mechanics, ASCE, pp. 1973-1994.

[3] Been, K. and Jefferies, M.G. (1985). “ A state parameter for sand.” Geotechnique Vol. 35, p 99-112.

[4] Cubrinovski, M. (1993). "A constitutive model for sandy soils based on a stress-dependent density parameter” Ph.D. Thesis Report, University of Tokyo.

[5] Cubrinovski, M. and Ishihara, K. (1998). "Modeling of sand behavior based on state concept ." Soils and Foundations, JGS, vol.38,p 115-127.

[6] Cubrinovski, M. and Ishihara, K. (1998). "State concept and modified elastoplasticity for sand modeling." Soils and Foundations, JGS, vol.38, p 213-225.

[7] Cubrinovski, M. and Ishihara, K. (2000). "Flow potential of sandy soils with different grain compositions." Soils and Foundations, JGS, vol.40, p 103-119.

[8] Cubrinovski, M. and Ishihara, K. (2002). "Maximum and minimum void ratio characteristics of sand." Soils and Foundations, JGS, vol.42, p 65-78.

[9] Desia / Siriwardane, (1984), " Constitutive Laws for Engineering Materials with emphasis on geologic material .” Prentice-Hall, pp. 241-243,

[10] Hicher, P.Y. (1996). "Elastic properties of sand.” Journal of Geotechnical Engineering, ASCE, p 641-648.

[11] Jha, K.K. (2000). "State concept and its application in plane strain problem” M.Sc. Thesis Report, Saitama University.

[12] Jha, S.K.(2004). "Strength And Deformation Characteristics of Bagmati River Sand based on Steady State Concept" M.Sc. Thesis, Institute of Engineering, Pulchowk Campus.

[13] Jha,K.K. and Suzuki, K. (2001).” Behavior of sand based on its characteristic states. " Research report of Dept. of Civil and Environmental Engg., Saitama University, p 11-23.

[14] Li.,X.S., Dafalias, Y.F., (2000). “ Dilatancy for cohesionless soils " Geotechnique, p 449-460.

[15] Liu Huabei and Ling ,Hoe I. (2002). “A sand model based on the generalized plasticity. " $15^{\text {th }}$ ASCE Engg. Mechanics Conference, Columbia University.

[16] Momen, H. and Ghaboussi, J., (1982), " Stress dilatancy and normalized work for sands ." IUTAM Conference on Deformation and Failure of Granular Materials/Delft, pp. 265-274.

[17] Poul V. L. and Jerry A. Y. (1996). “ Undrained sand behavior in axisymmetric tests at high pressure.” Journal of Geotechnical Engineering, ASCE, p 120-129.

[18] Poulos, S. J (1981). "The steady state of deformation." Journal of Geotechnical Engg., ASCE, Vol.107, p 553-562.

[19] Scott, F. R. (1827). "Plasticity and Constitutive relations in soil mechanics" ASCE, p 563-605.

[20] Verdugo, R. (1992), "Characterization of sand soil behavior under large deformation,” Dr. Eng. thesis, Univ. of Tokyo.

[21] Verdugo, R. and Ishihara, K. (1996). " The steady state of sandy soils.” Soils and Foundations, JGS, vol.36, p 81-91.

[22] Wang, Zhi-Liang, Dafallias, Yannis F., Li, Xiang-Song and Makdisi, Faiz I. (2002). "State pressure index for modeling of sand behavior." Journal of Geotechnical and Geoenvironmental Engg., ASCE, p 511-519. 